\title{
O marketing é a mensagem
}

\author{
Marketing is the message
}

\author{
El marketing es al mensaje
}

\section{Manoel Marcondes Machado Neto}

- Líder do grupo "Gestão e marketing na cultura" (CNPq)

- Professor adjunto da Faculdade de Administração e Finanças da Universidade do Estado do Rio de Janeiro (UERJ)

- Coordenador do curso de "Marketing cultural: gestão, finanças e indústria criativa", da UERJ

- Doutor em Ciências da Comunicação pela Escola de Comunicações e Artes da Universidade de São Paulo (ECA-USP)

- Mestre em Comunicação pela Universidade Federal do Rio de Janeiro (UFRJ)

- Especialista em Análise de Sistemas e Métodos pelo Saint Charles CPE (Illinois, EUA)

- Graduado em Relações Públicas pelo Instituto de Psicologia e Comunicação Social da UERJ

- Autor dos livros Marketing cultural: das práticas à teoria (2005) e Relações públicas e marketing: convergências entre comunicação e administração (2a. edição, 2008)

- Consultor de empresas desde 1980

- Editor do website marketing-e-cultura.com.br desde 1999

- marcondesneto@yahoo.com 
Vencida a etapa de projetos artístico-culturais pontuais, evoluindo a concepção a um patamar de política (no Estado e nas empresas) e, principalmente, abandonando o vício - antes virtude - do incentivo fiscal (típico caso de remédio que se torna um veneno), a aplicação do conceito de marketing à produção artístico-cultural chega a um tempo de maturidade e novas proposições na forma de trabalhar, de se levantarem fundos e de se buscarem financiamentos, dando bases ao surgimento de uma economia da cultura.

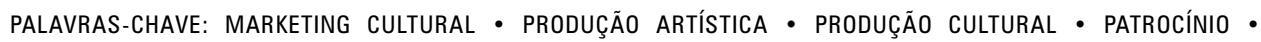
RELAÇÕES PÚBLICAS

\section{Abstract}

After the stage of specific artistic and cultural projects, evolving the concept to a level of politics (in countries and firms) and, particularly, breaking the habit - formerly virtue - of the tax incentive (typical case of medicine that becomes poison), the application of the marketing concept to artistic-cultural production comes at a time of maturity and of new proposals for the way of working, of raising funds and of securing financing, giving rise to emergence of a culture economy.

KEYWORDS: CULTURAL MARKETING • ARTISTIC PRODUCTION • CULTURAL PRODUCTION • SPONSORSHIP • PUBLIC RELATIONS

\section{Resumen}

Superada la etapa de los proyectos artísticos y culturales aislados, con la evolución de la concepción a un nivel de política (en el estado y en las empresas) y, sobre todo, con el abandono del vicio (antes, virtud) de las ayudas fiscales (caso típico de remedio que se convierte en un veneno), la aplicación del concepto de marketing a la producción artístico-cultural alcanza un momento de madurez y de nuevas propuestas en las formas de trabajar, de recaudar fondos y de financiarse, que sientan las bases para el surgimiento de una economía de la cultura.

PALABRAS CLAVE: MARKETING CULTURAL • PRODUCCIÓN ARTÍSTICA • PRODUCCIÓN CULTURAL • PATROCINIO • RELACIONES PUBLICAS 
Cultura, cosa mentale.

Umberto Eco

uarenta anos separam dois artigos seminais: "Miopia em marketing” (1960), de Theodore Levitt (1960), e "Esqueça o marketing” (2001), de Mitsuru Yanaze. Essas quatro décadas formataram o que hoje chamamos de mundo civilizado (?!) do pós-guerra - aquele em que $20 \%$ da população consomem $80 \%$ dos recursos naturais do Planeta. Há quem preferisse manter o desenvolvimento sob as rédeas do Estado - os casos (execrado) de Cuba e (aplaudido) da China. Outros, por sua vez, maravilham-se com as benesses de uma mentalidade centrada no consumo.

O que testemunhamos nesse período é uma transição do modelo meramente "vendedor", centrado no produto, para uma exacerbação do modelo "mercadológico", centrado no consumidor - o marketing concept, ou "espírito de marketing", na tradução de Vasconcellos, ou seja, "produzir o que vende ao invés de vender o que se produz” (VASCONCELLOS, 2006, p. 59).

Trazendo a discussão para a esfera de interesse das relações públicas, temos que o marketing se constitui, também, em um modo de relacionamento (McKENNA, 1997), principalmente no que toca ao comportamento de consumo - e não esqueçamos que em arte o termo mais aplicável não é "consumo", mas fruição. A relação, no caso, é aquela entre o artista, grupo artístico ou espaço cultural e sua clientela (seus "consumidores").

Se, para Kotler (1994, p. 513) "as empresas também devem comunicar-se com seus consumidores atuais e potenciais - inevitavelmente, qualquer empresa exerce o papel de comunicadora ou promotora", não será diferente com o artista, grupo artístico ou a organização artístico-cultural (museu, centro cultural, orquestra, companhia de dança etc.).

Museus - nos Estados Unidos - têm um grande interesse em saber mais sobre as características de seus não-usuários, usuários esporádicos e usuários frequentes [...]. De acordo com estimativas apuradas por Falk (1993) os não-usuários são metade da população [...]. Usuários esporádicos são considerados os que visitam os museus anualmente e usuários frequentes são aqueles que vão ao museu várias vezes no ano - e esses têm maior potencial de vir a ser membros como voluntários ou mesmo contribuintes [...] estimados 63 milhões de cidadãos adultos não visitaram sequer uma única instituição cultural durante o ano anterior (1992) (KOTLER; KOTLER, 1998, p. 103) 


\section{A COMUNICACÃO INTEGRADA E O SURGIMENTO DA EXPRESSÃO "MARKETING CULTURAL"}

Posto em prática nos maiores conglomerados organizacionais do Planeta desde os anos 1980, as chamadas integrated marketing communications impuseramse como objeto de pesquisa.

Coube a Margarida Kunsch, pioneiramente, em 1986 - coincidentemente também o ano de début da Lei Sarney -, com seu enunciado do composto da comunicação integrada, incluir entre as atividades de comunicação institucional o marketing cultural. Foi a primeira abordagem científica, fruto da observação atenta da pesquisadora quanto às atividades crescentes de patrocínio institucional às artes por grandes empresas brasileiras. Esse movimento foi ensejado, principalmente, por aquela lei de incentivo à cultura (Lei 7.505), baseada na renúncia fiscal de parte do imposto de renda devido. Alguns antecedentes também devem ser citados: "O marketing cultural é uma das ferramentas de comunicação mais seguras para que o produto associado a determinado evento tenha reforçada a imagem desejada” (MUYLAERT, 1993).

Tal definição - eminentemente instrumental - ainda é válida para a grande maioria das iniciativas que vemos rotuladas como sendo "ações de marketing cultural”. Segundo Gisele Marchiori Nussbaumer (1999, apud MACHADO NETO, 2000, p. 92),

se ao artista impôs-se um mercado da cultura, cabe a ele aprender a lidar com esse mercado. Se o marketing passou a ser uma exigência para sobreviver no mercado da cultura, então cabe ao artista buscar nele as adequações necessárias para que possa, através da sua utilização, criar ou ocupar brechas antistatus quo no interior desse mercado.

Em seu website, www.cultura.gov.br, o Ministério da Cultura define assim o marketing cultural:

O marketing cultural ainda é uma experiência recente não só no Brasil como no mercado internacional de patrocínio, constituindo-se num tipo de estratégia sofisticado, voltado para a consolidação da imagem da empresa, com retorno obtido a médio ou a longo prazo. As empresas pouco a pouco começam a perceber os seus benefícios, embora um contingente importante, ou por desconhecimento em relação a suas técnicas e potencialidades, ou por desconfiança em estabelecer uma ligação mais estreita com alguma área artística, ou, ainda, por preferirem outras linhas de marketing (social, esportivo etc.), ainda continua resistente a esse instrumento.

Margarida Kunsch defende que a expressão "marketing cultural” nada mais é do que "outro nome para designar atividades de relações públicas: o patrocínio e a promoção institucional”. 
É, pois, necessário, que artistas e grupos artísticos (orquestras, companhias de dança, teatro e ópera), preferencialmente por meio de seus produtores, além das próprias instituições culturais, se constituam em entes capacitados em marketing - e aí compreenda-se a atividade na sua abordagem clássica, ou seja, um processo abrangente que vai desde a concepção do "produto" ou do "serviço" cultural até a sua distribuição no mercado (verdadeiro nó górdio da área), passando pela sua viabilização físico-financeira e divulgação. Esse raciocínio aproxima o marketing das relações públicas porquanto parte de duas premissas:

1. A comunicação faz a intermediação entre a produção artístico-cultural e o público e, por definição, essa função mediadora é a principal base de formação e de ação do profissional de comunicação e, em especial, do relações-públicas;

2. O artista, o grupo artístico ou a organização artístico-cultural necessitam exercer um discurso, uma voz, e ostentar uma atitude, uma face pública. Enfim, estabelecer um relacionamento com o seu meio externo. Tais desafios demandam um trabalho profissional especializado.

A integração dessas duas vertentes tornam pertinente a tese de que o relaçõespúblicas representa o profissional com o perfil verdadeiramente adequado para a atuação em marketing cultural - ideia defendida em artigo por nós publicado na revista Organicom (MACHADO NETO, 2006, p. 109) ${ }^{1}$.

\section{MARKETING NA CULTURA}

De fato, a ótica da produção em escala e a aplicação do marketing concept não poderiam ser ignorados por um segmento que assume cada vez mais relevância na vida de indivíduos, de localidades e de nações: o da fruição da arte como cultivo da mente - a cultura. Mas ainda ficam! É dessa exclusão que trata o presente artigo.

Observe-se que não nos referimos ao marketing exercido pela chamada indústria cultural - e aqui utilizamos o conceito ipsis litteris dentro da compreensão dada por Adorno e Horkheimer (1986, p. 113-156). Este encontrase muito bem aplicado por emissoras, editoras e produtoras mundo afora, inclusive no Brasil. Referimo-nos, sim, ao espírito de marketing aplicado

1 A validação de uma teoria para marketing cultural deu-se a partir do estudo dos seguintes casos: Accenture (São Paulo), Centro Cultural Banco do Brasil (Rio de Janeiro), Cia. Cacique de Café Solúvel (Londrina), Dell'Arte Soluções Culturais, Museu de Arte Moderna de São Paulo e Petrobras (Rio de Janeiro). Os casos: situações reais de mercado em que estratégias de marketing aliadas às táticas de marketing cultural produziram, de fato, os efeitos benéficos de uma política institucional de apoio à arte e à cultura. 
(ou ainda não aplicado) à ação cultural, tal como a define Teixeira Coelho $(1986)^{2}$.

A cultura como manifestação e uso/ consumo popular, fora das grandes corporações na mídia - sim, porque a mídia é o grande vetor dos conteúdos que encerram cultura -, é que carece de aplicação dos conceitos e instrumentos de marketing, voltados à sua produção, disseminação e fruição. Bem entendido que não incluímos - propositadamente - a concepção, pois que esta não se sujeita ao pensamento mercadológico quando se trata de manifestação artística base de muito daquilo a que atribuímos a aura de "cultural".

\section{Implicações do "produto" (hoje, na verdade, "proposta de valor")}

Uma vez identificados o mercado-alvo da ação cultural (e esse trabalho não está a cargo do artista, mas de seu produtor) e suas características, deve-se decidir sobre o formato da proposta que veiculará o produto do trabalho artístico (é preciso, sempre, tentar eliminar o preconceito que, ainda, muitos criadores têm em admitir que o fruto de seu trabalho seja tratado como um produto - o que, de fato o é, sua proposta de valor) e refletir sobre a resposta desejada da audiência (MACHADO NETO, 2008, p. 240).

\section{Implicações de distribuição (o nó górdio do marketing cultural - "ir aonde o povo está")}

Para os produtos da ação cultural, o que garante sua distribuição e consequente fruição é uma política cultural de Estado; a garantia de que uma política de cultura seja reconhecida pela cidadania no plano nacional (a exemplo do que já ocorre com a saúde e a educação) está baseada na existência de pelo menos uma diretoria específica destinada à cultura em cada município e na implantação dos pontos de cultura, em todos os 5.565 municípios brasileiros - este, o principal instrumento de democratização da Política Nacional de Cultura $(2005)^{3}$.

2 Para Teixeira Coelho, "promover a cultura não é, apenas, financiar o artista, o produtor individual, como (mal) vem fazendo o Estado no Brasil, há décadas: é, antes, criar as condições para que o maior número possível de pessoas tenha acesso ao sistema de produção cultural, senão como produtores, pelo menos como consumidores efetivos. E cultura não é a simples soma, o estoque de produtos culturais acabados, prontos, mas um "modo de vida" entre esses produtos: no primeiro caso o que se tem é a cultura-inerte; apenas no segundo é que surge a cultura-ação. Mal ou bem, mais mal do que bem, o Brasil já tem seu estoque de cultura-inerte; trata-se agora de fazê-lo circular, de torná-lo ação".

3 Cf. Programa "+Cultura" do Governo Federal (www.cultura.gov.br). 


\section{Implicações de preço}

O preço (do ingresso, do livro, do CD, do DVD) tem que atender a dois reclamos: a viabilização tanto do trabalho do artista quanto do consumo (ou da fruição, melhor dizendo) de sua produção pelo público-alvo.

\section{Implicações de promoção}

(comunicação/divulgação)

A comunicação de marketing tem que ser correta, pertinente e adequada, sem o que não levará o público ao encontro da arte/produção em pauta.

Configura-se, assim, a aplicação do "composto de marketing" (McCARTHY, 1976) às atividades artístico-culturais.

\section{"MANAGEMENT" A SERVIÇO DA SOLUÇÃO DE UM PARADOXO}

Autores consagrados como Peter Drucker e Philip Kotler desenvolveram reflexões sobre a aproximação aparentemente paradoxal - entre as artes e o marketing. Paradoxal porque a arte se dá, com as exceções que Tom Jobim sabiamente chamou de "as encomendas", como manifestação do espírito, de um indivíduo ou de um grupo artístico, apenas obediente à pulsão do(s) seu(s) criador(es). Por seu turno, o marketing é, tão somente, o processo de produção de algo que venha a atender uma demanda específica e expressa de um indivíduo ou grupo. $\mathrm{Na}$ administração desse "meio de campo" é que entre o especialista em marketing cultural.

\section{NO INÍCIO ERA O VERBO}

A literatura precede, cronológica e "maternalmente", os outros gêneros da arte: o poema escrito ou proferido, a peça teatral encenada, o filme que acompanha as pipocas - e por aí vai.

Exceção a essa regra é a da arte plástica (pictórica ou tátil) - vertente que também apaixonou "mecenas" ao longo da história.

O livro - filho dileto das letras - é, já de longe, a mais incentivada das produções culturais. Legislação diversa "protege" o livro, tornando-o imune a impostos. E mesmo assim o livro brasileiro está entre os mais caros do mundo. Segundo consta de estudos da ainda enigmática "cadeia produtiva do livro", até $75 \%$ de seu preço de capa ficam nas mãos da distribuição ${ }^{4}$.

4 Levantamento feito no site www.submarino.com. 
Levando-se em conta que o autor recebe $10 \%$ do preço de capa, restam apenas $15 \%$ para o empreendedor-editor - o que, obviamente, não remunera e não motiva um negócio que se pretenda autossustentável. Tal estrutura de custos talvez explique os altos preços de livros no Brasil.

Por outro lado, floresce uma rica atividade editorial "de luxo", sob a - aqui, redundante - legislação de incentivo à cultura. Editoras remuneram-se duplamente, para além das margens de lucro em virtude de preços proibitivos, com patrocínios oriundos da renúncia fiscal, em várias esferas.

\section{MARKET}

Um locus chamado market ganhou corpo na era medieval. Nele, a ação desenvolvida por atores-comerciantes e atores-consumidores não é outra senão a de marketing, seja como permuta ou escambo, seja como relação mercantil após o surgimento da moeda de reserva.

E, nesse mesmo lugar, o "mercado", logo depois dos gêneros de primeira necessidade, surgiram artistas circenses - declamadores, atores, menestréis, mágicos, músicos. Entretinham o público. Não possuíam espaço demarcado - eram saltimbancos. E não ganhavam senão os trocos atirados na capa empoeirada das caravanas.

No tempo dos feudos e, depois, dos burgos, nobres passaram a trazer para dentro das muralhas seus "próprios" artistas, mirando-se nos príncipes e reis e seus bobos da corte - por toda a Europa.

A esses "protegidos" restava criar e entreter os nobres em troca de sua própria sobrevivência - um embrião de profissão -, ao mesmo tempo em que outras corporações de ofício iam surgindo. Artistas têm, pois, a mesma "idade" de tecelões, carpinteiros, mercadores e transportadores.

Por sua vez, a todo-poderosa Igreja Católica já cuidava de seu patrimônio (muito) material e, igualmente aos temporais sacro-imperadores, "contratavam” artistas plásticos para ornar seus templos e compositores e músicos para os ofícios religiosos cada vez mais grandiloquentes. De novo, as encomendas.

Patrocinadores primordiais, reis e papas muito fizeram pela música, pela pintura e pela escultura, a exemplo do que Mecenas fizera 1.600 anos antes, no século I a. C., em Roma. E não se fala mais de história.

\section{(N)O FIM É A VERBA}

Dando um salto milenar, encontramo-nos no Brasil, país que criou incentivo fiscal à cultura há quase um quarto de século (a Lei Sarney é de 02 de julho de 
1986). É de se perguntar se a cultura dos brasileiros melhorou nessa quadra em que o Estado delegou o grosso de suas verbas aplicadas em cultura ao arbítrio de executivos de marketing. A resposta é, infelizmente, não.

Para efeito de ilustração cabe citar matéria publicada pelo jornal Brasil Econômico (2010, p. 3-8):

O Governo Federal tenta acabar com a Lei Rouanet. O projeto de lei discutido no Congresso Nacional, chamado Pro-Cultura, elimina o benefício de dedução no imposto de renda das empresas de $100 \%$ do valor aplicado em projetos culturais. Se aprovada, a nova legislação limita o valor máximo para dedução em $80 \%$.

A reforma da Lei Rouanet divide opiniões. O modelo de financiamento de cultura estabelecido pela Lei Rouanet, de 1991, está em rediscussão. Os debates em torno do projeto de lei $6.227 / 2010$, que tramita no Congresso e propõe a revogação do atual sistema, opõem empresas, produtores culturais, advogados e artistas. Não há consenso sobre a forma mais eficiente de estimular a iniciativa privada e apoiar o desenvolvimento de projetos culturais.

O receio da classe artística é de que a mudança da lei possa afugentar as empresas do investimento em projetos culturais - ou, pelo menos de imediato, do teatro, da música e das artes plásticas -, já que dispositivos específicos garantem a esses segmentos a captação de $100 \%$ do orçamento com verba pública.

O argumento dos defensores da mudança é que, em 19 anos de existência, a Lei Rouanet não atingiu a meta de formar um mercado de cultura.

De fato, após 24 anos de incentivos fiscais, não se criou - como esperado (todo incentivo fiscal é, por natureza, concedido por tempo definido) - uma cultura empresarial de apoio à cultura.

A separação entre educação e cultura, ocorrida em 1985 (um ano antes da Lei Sarney), revelou-se desastrosa. Embora a primeira não viva sem a segunda, a educação tem tido orçamentos federais médios cinquenta vezes superiores aos da cultura. E com toda essa "riqueza", ainda livrou-se de cuidar do acervo cultural relegado a um ministério desidratado e "desimportante" ${ }^{5}$, mesmo tendo

5 Escreveram Christian Klein et al. (1999, p. 4): “A confusão de informações truncadas e declarações infelizes que se seguiram ao anúncio das modificações nas estratégias políticas do Ministério da Cultura teve seu lado bom. Há muito tempo não se questionava tanto o papel de uma pasta considerada de segunda classe pelo alto escalão de Brasília. 0 diretor de teatro Aderbal Freire-Filho vai logo aumentando a temperatura da fogueira: para ele, mais do que discutir a função do Ministério da Cultura, a polêmica serviu para se questionar a real importância do cargo. Aderbal lembra que, durante a reforma ministerial que se sucedeu à reeleição de Fernando Henrique, os partidos se engalfinhavam para ocupar o maior número de pastas. 0 único ministério que não despertava a gula dos políticos era justamente 0 da Cultura. 'Além de verbas minúsculas, o Ministério da Cultura padece de desimportância política. É o próprio presidente da 
evoluído - em 2005 - para a promulgação (longe, porém, da implementação de fato) de uma acalentada Política Nacional de Cultura.

A fenomenologia do chamado "marketing cultural", objeto que tivemos que definir, conceituar ${ }^{6}$, privilegiou a visão do sujeito-patrocinador - o verdadeiro beneficiado pelas legislações (federais, estaduais e municipais que surgiram a partir da pioneira Lei Sarney) até aqui. Trata-se de uma visão distorcida, embora típica de marketing, que privilegia uma demanda de público-consumidor, não de arte, mas do produto, serviço ou organização patrocinadoraanunciante.

\section{ESTRANHAMENTO}

No princípio - década de 1980 - a academia torceu o nariz para o termo "marketing cultural" adotado e difundido pela mídia. Sem ter correspondente no idioma-pátrio do marketing, este parecia mais um rótulo fadado ao desprezo pelos estudiosos dos processos de criação artística ou de difusão cultural. Coelho Neto (2004), mesmo onze anos após a criação da lei que suscitou um debate sobre a crescente prática empresarial, não consignou o verbete, que é criação, por sinal, eminentemente nacional.

Ora, admite-se existir um PIB da cultura. E admite-se existir uma economia da cultura. Se se admite que existem bens eminentemente culturais e um mercado de consumo de cultura, não se pode negar a existência de um marketing cultural. Ao market, como já visto, sucede-se um processo de marketing. Se a indústria automotiva (precursora da aplicação do marketing concept), pratica um marketing automobilístico, se os laboratórios praticam um marketing farmacêutico e os bancos praticam um marketing financeiro, o setor cultural, por analogia, praticaria um marketing cultural - e aí reside um dos principais problemas - até hoje - de compreensão do termo. Não se trata do marketing da indústria cultural, mas, principalmente das práticas postas pela "ação cultural".

O marketing da indústria cultural vai muito bem, obrigado. Jornais, rádios, tevês e editoras nunca faturaram tanto. O marketing cultural praticado por patrocinadores-anunciantes, também. E, afinal, patrocínio de artes e espetáculos por organizações públicas e privadas é algo muito antigo e consolidado. $\mathrm{Na}$ verdade, esse "marketing” não precisaria de novo rótulo para chamar atenção.

República que reconhece esta desimportância ao tratar o ministério como um enfeite, que tanto faz como tanto fez', diz. 0 também diretor Amir Haddad concorda: 'Um ministério pouco respeitado pela cúpula do poder não consegue nada. Vamos ser sinceros: nunca houve planejamento ou política cultural no país. Há definição de táticas e políticas, mas só se discute política econômica. Política cultural no Brasil somos nós pedindo dinheiro para nossos projetos. E isso é muito pouco [...]".

6 Atividade deliberada de viabilização físico-financeira de produtos e serviços que, comercializados ou franqueados, vêm atender às demandas de fruição e enriquecimento cultural da sociedade. 
A esse tipo de ação denominamos marketing cultural de meio - aquelas práticas em que o apoio à arte e à cultura se dá como meio de promoção institucional.

O foco principal de nossa atenção é aquele que se pode jogar não sobre os produtos e serviços da indústria cultural, esses já muito bem vendidos. O objeto passa a ser o que chamamos, a partir de uma taxonomia proposta nem nossa tese, de "modalidades alternativas" de marketing cultural, ou seja, aquela fenomênica na qual a relação sujeito-objeto não é a da indústria cultural, mas a da visão que parte dos artistas ou grupos, empreendedores e organizações ou espaços autônomos para o fazer artístico-cultural.

\section{A APLICAÇÃO DO MARKETING CONCEPT ÀS ARTES}

São essas as modalidades de práticas (segundo o seu locus/fato gerador):

1. Marketing cultural de fim: aquelas ações nas quais o processo se dá tendo como objeto finalístico de sua existência/atuação social, a produção e a difusão da cultura: Exemplos: Funarte, Osesp, MAM.

2. Marketing cultural de agente: as ações nas quais o processo abrange todo o marketing mix, em empreendimento sob risco, com recursos próprios ou de terceiros. Exemplos: Dell'Arte, Dançar Marketing.

3. Marketing cultural misto: as ações que misturam duas ou mais modalidades, como as anteriores, principalmente pela escassez de recursos ou por oportunismo político (ações privadas em espaços culturais públicos, parcerias entre instituições culturais estatais e empresas ou, simplesmente, co-patrocínio ou multi-patrocínio, quando, para efeitos de retorno mercadológico de imagem, há uma certa dispersão por conta do que chamamos de "salada de marcas").

\section{ALGUMAS CONSIDERAÇÕES SOBRE UM "NOVO" MARKETING}

Embora um marketing de negócios pudesse ser considerado "do bem”, ao lado do que Patricia Aburdene denomina "capitalismo consciencioso", a versão "má" do marketing é a que prevalece. Irônica e controvertidamente, o próprio ministro da Cultura, Juca Ferreira, chama os mínimos aportes-contrapartida (em média de 10\%) sem incentivos fiscais de "dinheiro bom". Quem é o verdadeiro vilão da história? O marketing (privado) ou o dinheiro "mau” (público)? Cite-se aqui Bruno Mello (2010), no site www.mundodomarketing.com.br:

O marketing como conhecemos está morto. Pelo menos é o que afirma Kevin Roberts, CEO Global da agência de publicidade Saatchi \& Saatchi. O autor do best seller "Lovemarks", no entanto, reconhece que o marketing de massa ainda sobrevive. O problema é que ele vive em um ambiente que não 
existe mais. É o que Roberts chama de "v-u-c-a", (na sigla em inglês), um mundo volátil, incerto, complexo e ambíguo. E vai além: não é um mundo para estratégias tradicionais. O publicitário propõe ainda a retirada da missão e da visão da parede das empresas. No lugar, elas precisam ter um sonho que engaje as pessoas.

Nem tudo isso chega a ser tão subversivo para Kevin Roberts. Afinal, quando foi CEO da Pepsi no Canadá, ele simplesmente metralhou - literalmente - uma vending machine da Coca-Cola ao final de uma convenção de vendas onde o foco era a concorrência com a marca mais valiosa do mundo. Agora, o publicitário inspira os profissionais de marketing a saírem de seus escritórios, deixarem de ver e-mails, de ler pesquisas e passarem a conhecer os sentimentos de seus consumidores para transformar suas marcas em "Lovemarks", ou marcas amadas.

Para isso, o departamento de marketing deve se transformar em um "departamento de movimento". Um movimento para a marca. "Tem que fazer com que as pessoas se mexam pelo raciocínio emocional”, afirmou Kevin Roberts, durante seminário realizado pela HSM, em São Paulo. "O que importa é como as pessoas se sentem. É o sentimento que move as pessoas”, aponta.

\section{Emoção $=$ Ação $=$ Envolvimento}

A empresa que focar no sentimento do consumidor poderá ter vantagem. "Os seus concorrentes estão pensando com a cabeça. Siga a intuição. Pense e ouça com o coração", recomenda. "O marketing não é mais movido por mídia, de um para muitos, mas de muitos para muitos. Distração não funciona mais. As pessoas querem interação", salienta. Mas como colocar a marca no coração do consumidor?

A Ikea respondeu colocando sofás no metrô na Europa e a Netflix fez o que Roberts chama de surpreender com o óbvio: ao invés do cliente ir buscar o filme na locadora, a locadora entrega em sua casa. "Perdemos muito tempo fazendo coisas burocráticas e não assumimos riscos. O orçamento não deixa você alçar novos voos porque está preso aos números do ano passado", ressalta.

Consequência do marketing, as marcas também estão mortas na opinião de Roberts. "As marcas estão mortas porque se "comoditizaram". Elas morreram porque fazem as mesmas coisas", explica. "Abram mão de controlar a marca. Uma lovemark não é da empresa. É do consumidor”. A mudança também deve acontecer na mensuração dos resultados. Neste caso, sai de cena o Retorno sobre o Investimento e entra o Retorno sobre o Envolvimento dos Consumidores.

Uma lovemark cria lealdade para além da razão. "Você pode substituir o seu iPod por qualquer outro MP3, mas não quer, quer? Olhe para a embalagem de seu produto e se pergunte se ele é irresistível. O consumidor quer novas 
soluções e inovações. E isso não se torna real por meio de estatística, mas por loucos que acreditam nas marcas ao ponto de tatuá-las em seu corpo", assegura o publicitário.

Por isso, a empresa e a marca devem ter uma inspiração. "As pessoas não querem metas, elas querem trabalhar por um sonho, algo que as mova. Você não vai vencer o concorrente fazendo marketing tradicional. É preciso ter ideias loucas. Temos que ter uma cultura que inspire a transformação. Não há limites para o que você pode fazer", aponta Kevin Roberts.

Quais são as lovemarks na área da arte e da cultura? Osesp? TV Cultura? Funarte? Fundação Roberto Marinho? MAM? Som Livre? Ballet Stagium? Pinacoteca do Estado? CCBB? Grupo Corpo? OSB? Orquestra Petrobras Sinfônica? Museu da Língua Portuguesa? Canecão? Cordão do Bola Preta?

Retirando-se dessa lista acima as instituições participantes da indústria culturalou de mainstream - pouco resta.

A propósito, há quem critique e estigmatize o conceito de indústria cultural tal como descrito por Adorno e Horkheimer em 1944, mas, como se pode comprovar em artigo de Bernard Stiegler (2010, p. 4 e 5), a indústria cultural nunca esteve tão indústria como neste século XXI. Citemos o autor:

O capitalismo hiper-industrial se desenvolveu a tal ponto que, a cada dia, milhões de pessoas se conectam simultaneamente aos mesmos programas de televisão, de rádio ou de consoles de "games". O consumo cultural, metodicamente massificado, não é algo sem consequências sobre o desejo e a consciência.

Uma fábula vem dominando os últimos decênios, iludindo grande parte de pensadores políticos e filósofos. Narrada após 1968, ela queria nos fazer crer que estávamos entrando na era do "tempo livre", da "permissividade" e da "flexibilidade" das estruturas sociais - em suma, na sociedade do lazer e do individualismo. Teorizado sob o nome de sociedade pós-industrial, esse conto influenciou e fragilizou especialmente a filosofia pós-moderna. Inspirou os social-democratas afirmando que já tínhamos passado pela fase das massas trabalhadoras e do consumo da era industrial para a temporada das classes médias. O proletariado estaria em vias de desaparecer.

Não somente em termos numéricos, este último continua muito importante, como os trabalhadores continuam se "proletarizando", ou seja, seguem a serviço de um dispositivo mecânico que os priva de iniciativas e do saber profissional. Quanto à classe média, falar de desenvolvimento de lazeres - no sentido de tempo livre e de todas as restrições de uma "disponibilidade absoluta" - não se reverte em nada concreto, porque esse mecanismo não tem por função liberar o tempo individual, mas sim controlá-lo para hipermassificá-lo. Esses são 
os instrumentos de uma nova servidão voluntária. Produzidos e organizados pelas indústrias culturais e pelos programas, eles formam aquilo que o filósofo francês Gilles Deleuze chamou de sociedades de controle. Estas, por sua vez, desenvolvem esse capitalismo cultural e de serviços, que fabricam todas as peças dos estilos de vida, transformam o quotidiano segundo seus interesses imediatos, padronizam as existências através de "conceitos de marketing".

De acordo com Deleuze, o marketing torna-se, sobretudo, o "instrumento de controle social", enquanto a sociedade pretensamente "pós-industrial" é, pelo contrário hiperindustrial. Longe de se caracterizar pelo predomínio do individualismo, os nossos dias parecem estar mais associados com algo que se torna gregário aos comportamentos e com a perda do indivíduo de forma generalizada.

Freud escreveu em 1930 que apesar de dotado pelas tecnologias industriais e atributos do divino, e "embora se assemelhe a Deus, o Homem de hoje não se sente feliz". É exatamente isso que a sociedade hiperindustrial faz com os seres humanos: os priva de individualidade, transformando-os em rebanhos de pessoas disfuncionais, produzindo um futuro defeituoso. Esses rebanhos desumanos cada vez mais tendem a se tornar furiosos: em sua obra, Freud analisa alguns loucos que tentaram retornar ao estado de horda, tomados pela descoberta da pulsão de morte - teoria revisitada por ele depois quando o totalitarismo, nazismo e antissemitismo estavam se espalhando pela Europa.

Embora Freud fale sobre a fotografia, o gramofone e o telefone, ele não evoca o rádio nem o cinema - então utilizados por Mussolini e Stalin, e posteriormente por Hitler - um senador americano afirmava já em 1912 que "trade follows films" - "o comércio seguirá o cinema". E ele nem imaginaria o poder da televisão. Os nazistas experimentaram uma primeira transmissão pública em abril de 1935. Enquanto isso, o alemão Walter Benjamin examinava o que chamou de "narcisismo de massa": o controle dessas mídias pelos poderes totalitários. Mas parece que ele também não conseguiu avaliar, para além de Freud, a dimensão funcional - em todos os países, inclusive nos democráticos - das emergentes indústrias culturais.

Por outro lado, Edward Bernays, sobrinho de Freud, teorizou amplamente sobre o tema. Ele explora as vastas possibilidades de controle daquilo que seu tio já havia chamado de "economia libidinal". Bernays estuda o desenvolvimento das relações públicas e técnicas de persuasão inspiradas pelas teorias do inconsciente que ele coloca a serviço do fabricante de cigarros Philip Morris em 1930 - enquanto Freud sente aumentar na Europa a pulsão de morte contra a civilização e pouco se importava com o que acontecia na América.

Esperou-se até a denúncia feita por Theodor W. Adorno e Max Horkheimer sobre o "estilo de vida americano" para que o funcionamento das indústrias culturais fosse verdadeiramente analisado. Mesmo que consideremos essas 
análises insuficientes, elas entendem que as indústrias culturais formam um sistema juntamente com todas as outras indústrias, cuja função consiste em fabricar comportamentos de consumo, massificando os estilos de vida. É, portanto, para assegurar o fluxo constante de novos produtos gerados pela atividade econômica que os consumidores não sentem desejo espontâneo; causando perigo endêmico da superprodução e, por conseguinte, a crise econômica, que não é possível combater sem por em risco todo o conjunto do sistema, cujo desenvolvimento, segundo Adorno e Horkheimer, é a própria barbárie.

Procuramos concentrar-nos, doravante, nas modalidades em que mais genuinamente se aplica o termo "marketing"; mais como processo de distribuição da produção e da riqueza e menos como termo sinônimo das práticas mercadológicas hiper-industriais cada vez mais massificantes, embora sob o rótulo de "customizadas", 1 to 1 (PEPPERS; ROGERS, 2001), personalizadas.

\section{NOVO OBJETO: UM MARKETING PARA AS ARTES}

Motivação básica da atuação no mercado artístico-cultural, primeiro produzindo, depois empreendendo e, finalmente, estudando o fazer artístico como molamestra do enriquecimento cultural da sociedade - encontra-se o desafio de um marketing muito específico e muito especial: o marketing aplicado às artes.

Trata-se de dotar os criadores autônomos, direta ou indiretamente - por meio de agentes ou produtores - de um olhar mercadológico sobre o seu trabalho. A perda do preconceito de chamar de "produto" o, agora, produto de seu trabalho artístico. Sem a visão típica de fazer aquilo que o mercado demanda (o que é natural na indústria cultural entre seus contratados), mas de - por meio da ação desse ente agente - "ir aonde o povo está", numa inversão de locus da "mercado-lógica", na qual o produto vai até seu fruidor e não o contrário.

Quando produtores artísticos, animadores culturais, agentes e relações-públicas de artistas e de corpos artísticos adotarem uma visão avançada de marketing cultural, totalmente fora da ideia de incentivos fiscais, muito do que permanece oculto (em ateliês, gavetas e rascunhos) ganhará público e tanto artistas quanto a sociedade beneficiar-se-ão desse incremento.

\section{UM ÚLTIMO DESAFIO PARA O MARKETING CULTURAL}

É preciso criar, no país, uma cultura de mecenato no seio da pessoa física. Não houve ainda, em nossa opinião, um adequado entendimento, pela sociedade, de que a pessoa física pode muito mais do que a pessoa jurídica no campo do apoio às artes e à cultura. Só para citar uma diferença legal já existente: a pessoa física pode abater até $6 \%$ de seu imposto de renda devido para incentivo a 
projetos culturais inscritos em nível federal, enquanto que as pessoas jurídicas só o podem fazer até o limite de $4 \%$ do mesmo imposto.

Quando a cidadania descobrir que lhe cabe o processo - não só do consumo, mas da sustentação da produção cultural -, chegaremos a novo patamar no qual a cultura será a mensagem, e não mais o marketing.

\section{REFERÊNCIAS}

ADORNO, Theodor; HORKHEIMER, Max. Dialética do esclarecimento. 2. ed. Rio de Janeiro: Zahar Editores, 1986.

COELHO NETO, J. Teixeira. Usos da cultura: políticas de ação cultural. Rio de Janeiro: Paz e Terra. 1986.

Dicionário crítico de política cultural. São Paulo: lluminuras. 2004.

KLEIN, Christian et al. Ministério questionado. Rio de Janeiro, Jornal do Brasil, Caderno B, 07 fev. 1999.

KOTLER, Philip. Administração de marketing. 4. ed. São Paulo: Atlas. 1994.

KOTLER, Neil; KOTLER, Philip. Museum strategy and marketing. San Francisco: Jossey-Bass Inc. Publishers. 1998.

KUNSCH, Margarida M. Krohling. Planejamento de relações públicas na comunicação integrada. 4. ed. - ver., atual. e ampl. São Paulo: Summus. 2003.,

LEVITT, Theodore. Marketing myopia. Harvard Business Review, . p. 45-56July-Aug. 1960.

MACHADO NETO, Manoel Marcondes. Relações públicas e marketing: convergências entre comunicação e administração. 2. ed. Rio de Janeiro: Conceito Editorial, 2008.

Marketing cultural: das práticas à teoria. 2. ed. Rio de Janeiro: Ciência Moderna, 2005.

Marketing para as artes: a evolução do conceito de marketing cultural e a importância desse campo de atuação para o profissional de relações públicas. Organicom, São Paulo, a. 3, n. 5, p. 109-119, 2006.

Marketing cultural: características, modalidades e seu uso como política de comunicação institucional. $2000.529 \mathrm{fl}$.

Tese (Doutorado em Ciências da Comunicação). ECA-USP, São Paulo.

McCARTHY, Jerome. Marketing básico. São Paulo: Editora Atlas, 1976.

McKENNA, Regis. Marketing de relacionamento. Rio de Janeiro: Campus. 1997.

MELLO, Bruno. 0 marketing morreu. 10/06/2010. Dlsponivel em: <http://www.mundodomarketing.com.br/9,14518,0-marketing-morreu-afirma kevin-roberts.htm>. Acesso em: 12 jun. 2010.

MUYLAERT, Roberto. Marketing cultural e comunicação dirigida. Rio de Janeiro: Editora Globo, 1993.

NUSSBAUMER, Gisele Marchiori. A cultura do Marketing. Revista Famecos, Porto Alegre, n. 10, jun. 1999.

PEPPERS, Don; ROGERS, Martha. Marketing 1 to 1. São Paulo: Makron Books, 2001.

STIEGLER, Bernard 0 desejo asfixiado. Le Monde Diplomatique Brasil. Edição de janeiro de 2010.

VASCONCELLOS, Manoel Maria. Marketing básico. Rio de Janeiro: Conceito Editorial, 2006.

YANAZE, Mitsuru H. (Org.). Marketing \& comunicação: funções, conceitos e aplicações. São Paulo: Editora STS, 2005.

Esqueça o marketing. Libero - Revista de Pós-Graduação da Faculdade Cásper Líbero, São Paulo, v. 3, n. 5, p. 88-92,

2001.

Recebido em: 01.07.2010 / Aceito em: 26.08.2010 